\title{
Microwave Ablation and/or Transcatheter Arterial Chemo- embolization in the Treatment of Hepatocellular Carcinoma
}

\author{
Sara R Abozaid ${ }^{1}$, Mustafa H Elshamy ${ }^{1}$, Ahmed A Alazim², \\ Soha A Elhawari ${ }^{1}$ \\ ${ }^{1}$ Department of Tropical Medicine, Faculty of Medicine, Zagazig University, Egypt. \\ ${ }^{2}$ Department of Radiology, Faculty of Medicine, Zagazig University,Egypt.
}

Corresponding Author Abozaid, Sara $R$

Mobile:

$+201273484371$

E mail:

dr_s5b5@yahoo.com

Key words: Hepatocellular carcinoma (HCC), Microwave ablation (MWA), Trans-arterial chemo-embolization (TACE)
Background and study aim: Percutaneous microwave ablation (MWA) and trans-arterial chemo-embolization (TACE) are established therapies for treatment of HCC patients. Lower rates of complete response with mono-therapies have been reported. Therefore, combined treatment strategies, including combined TACE and MWA have been used. The study aimed at comparing the efficacy of MWA mono-therapy; TACE monotherapy and combined TACE-MWA in the treatment of 3-5 cm HCC.

Patients and methods: The study prospectively included 102 patients with 113 hepatic focal lesions $(3-5 \mathrm{~cm})$ diagnosed as HCC by contrast-enhanced triphasic CT or dynamic MRI. Thirty-five HCC in 34 patients were subjected to MWA mono-therapy; 41 HCC in 34 patients were subjected to TACE monotherapy, while $37 \mathrm{HCC}$ in 34 patients were subjected to combined TACE-MWA therapy. Follow up by contrast-enhanced CT or MRI was done at one month, and every 3 months, up to one year after treatment. Therapeutic tumor response and local tumor progression were evaluated and compared among the groups.

Results: After one year follow up, the combined TACE-MWA group showed a higher rate of complete response (CR) $(83.3 \%)$ when compared to MWA group $(76.5 \%)$ and TACE group (66.6\%) $(\mathrm{P}>0.05)$. The local tumor progression (LTP) rate in the combined TACE-MWA group was lower $(16.6 \%)$ than that in MWA group $(23.5 \%)$ and TACE group $(33.3 \%)(\mathrm{P}=0.2)$.

Conclusion: Combined TACE-MWA therapy appears to be non-significantly superior to MWA mono-therapy and TACE mono-therapy in terms of complete tumor response and local tumor progression in patients with 3-5 $\mathrm{cm} \mathrm{HCC}$.

\section{INTRODUCTION}

Hepatocellular carcinoma (HCC) is a highly malignant tumor with elevated morbidity and mortality. HCC is the fifth among cancers and develops predominately in patients with liver cirrhosis [1,2]. Thermal ablation and trans-arterial chemo-embolization (TACE) are now well-established and widely used treatments for HCC [3-5].

According to the Barcelona Clinic Liver Cancer (BCLC) staging classification, liver resection, ablation, and transplantation are recommended treatments for early-stage HCC, while TACE is indicated in treatment of intermediate-stage $\mathrm{HCC}$ and multifocal tumors. However, this treatment classification in BCLC guidelines may be affected by other factors like tumor size, location, infiltration and tumors bridging more than one liver segment which may decrease the rates of complete response with mono-therapies [6-9]. Therefore, alternative treatments as combination therapy of TACE and thermal ablation are of growing interest.

Combination of radiofrequency ablation (RFA) and TACE has been shown to be more effective for induction of local tumor control and improvement of disease-free and overall survival of both medium-sized and large HCC tumors [10-12]. Nevertheless, percutaneous microwave ablation (MWA) can produce larger ablation zones and acquire 
faster ablations than RFA by preserving consistently higher temperatures inside the tumors $[13,14]$. Several studies, combining TACE and MWA were carried out for treatment of HCC. These studies either focused on treatment of small-sized $(<3 \mathrm{~cm}) \mathrm{HCC}$ or included a wide range of tumor size [15-18]. Therefore, this study aims at comparing the efficacy of MWA monotherapy; TACE mono-therapy and combined TACE-MWA in the treatment of 3-5 cm HCC.

\section{PATIENTS AND METHODS}

\section{Patients}

This prospective non-randomized study was carried out in Tropical Medicine and Radiology Departments, Zagazig University Hospitals, Egypt between March 2017 and November 2019. The study included 102 patients with 113 hepatic focal lesions $(3-5 \mathrm{~cm})$ diagnosed as HCC by contrast-enhanced triphasic CT or dynamic MRI.

Inclusion criteria were a) single hepatic focal lesion $(3-5 \mathrm{~cm})$ or multiple focal lesions (up to 3 tumors $\leq 3 \mathrm{~cm}$ ) with absence of vascular invasion or extra-hepatic metastasis; b) Child-Pugh A and B; c) performance status $0-2$; d) creatinine $<2 \mathrm{mg}$; e) bilirubin $<2 \mathrm{mg}$; f) platelets count $>50000$ and g) prothrombin concentration $>60 \%$. Exclusion criteria were a) previous treatment of $\mathrm{HCC}$, b) technical contraindications to percutaneous ablation or TACE, c) patients who did not fulfill the inclusion criteria.

According to multidisciplinary team decision, patients were enrolled in 3 groups according to technical eligibility and/or anticipated response to thermal ablation:

- Microwave ablation (MWA) group: included 34 patients with $35 \mathrm{HCC}$ lesions. The focal lesions received percutaneous MWA.

- Transarterial chemoembolization (TACE) group: included 34 patients with 41 HCC lesions. The focal lesions were deemed appropriate for TACE if thermal ablation is contraindicated as subcapsular lesions and lesions adjacent to main biliary branches. The focal lesions received maximum 3 sessions of TACE.

- Combined TACE-MWA group: included 34 patients with 37 focal lesions. The focal lesions were deemed appropriate for combined TACE-MWA therapy if the lesion was not well visualized by ultrasound or located in areas of higher recurrence rates. The focal lesion received MWA 2 weeks after TACE.

Patients were subjected to: a) medical history taking; b) physical examination including the ECOG scale of performance status [19]; c) laboratory tests- complete blood count- liver and kidney function tests- coagulation profilealphafetoprotein [AFP] and viral markers (anti$\mathrm{HCV}$ antibodies and HBsAg); d) modified Child - Pugh score [20]; e) pelvi-abdominal ultrasonography and f) abdominal contrastenhanced triphasic CT-scan or enhanced dynamic MRI.

\section{Diagnosis of HCC:}

Triphasic CT-scan or dynamic MRI was done for all patients to confirm the diagnosis. The typical hallmark is the combination of arterial phase hyperenhancement and washout on the portal venous and/or delayed phases [21].

\section{Patient management}

Microwave ablation (MWA): All patients were fasting (at least 6 hours) and under conscious sedation with propofol and midazolam. MTC-3 microwave generator (Amica, $2450 \mathrm{MHz}$ ) was used for MWA. The ultrasound examination (using a $3.5 \mathrm{MHz}$ probe; Esaote MyLab20Plus) was performed to determine the shortest puncture path and to refrain from the large blood vessels, the bile ducts, the gall bladder and the intestines. Ultrasound-guided puncture of the tumor was done by 14G MWA-antenna and the needle was withdrawn with applying $20-100 \mathrm{~W}$ to ablate the needle track and get $0.5-1 \mathrm{~cm}$ target ablation beyond the tumor boundary. MWA was performed once for patients of both MWA group and combined TACE-MWA group.

Trans-arterial Chemo-embolization (TACE): A $5 \mathrm{~F}$ catheter was introduced through the femoral artery by Seldinger technique and the angiogram of abdominal vessels was performed to visualize the arterial supply of the tumor. Then, the catheter was inserted into the artery supplying the tumor with injection of lipiodol $(10 \mathrm{ml})$, and doxorubicin $(30 \mathrm{mg}$ ) into the tumor followed by gelatin sponge particles embolization. At the end of the procedure, another angiogram was performed to ensure full embolization of the supplying artery. TACE was performed once for patients of combined TACE-MWA group and repeated for non-chemoembolized cases with maximum of 
three sessions for patients of TACE mono-therapy group.

\section{Follow-up and evaluation of therapeutic response:}

Abdominal contrast-enhanced triphasic CT-scan or enhanced dynamic MRI was performed at one month, and every 3 months, up to one year after treatment. Images were evaluated for the therapeutic tumor response and local tumor progression. The therapeutic tumor response was classified into complete response (CR); partial response (PR); stable disease (SD) and; progressive disease (PD). Disappearance of all target lesion(s) is considered complete response; decrease by $30 \%$ or more in the sum of longest diameter of target lesion(s) is considered partial response; while increase by $20 \%$ or more in the sum of the longest diameter of target lesion(s) is considered progressive disease. Stable disease is neither partial response nor progressive disease [22]. Local tumor progression (LTP) is defined as new nodular enhancement along the ablation margin or growth of the ablation zone on follow up imaging examination [23]. And, overall survival (OS) rate is the percentage of people in a study or treatment group who are still alive for a certain period of time after they were diagnosed with or started treatment for a disease. In this study, the OS is the percentage of patients who were still alive at the end of one year post treatment.

Moreover, post-treatment laboratory parameters and AFP level were measured. Procedure-related complications were assessed according to Society of Interventional Radiology (SIR) classification [24].

\section{Study endpoints:}

The primary endpoint was complete response and local tumor progression at the end of follow up period of 12 months after treatment. The secondary endpoints were adverse events and overall survival rate.

\section{STATISTICAL ANALYSIS}

Data were checked, entered and analyzed using SPSS statistical package. Data were expressed as mean \pm SD for quantitative variable, number and percentage for qualitative one. Chi-squared $\left(\mathrm{X}^{2}\right)$, ANOVA (F-test), and paired t test were used when appropriate. $\mathrm{P}$ value $<0.05$ was considered significant.

\section{RESULTS}

\section{Patient and tumor characteristics}

Demographic and baseline characteristics of MWA, TACE, and TACE-MWA groups are presented in (Table 1). Thirty five focal lesions in 34 patients were treated by MWA ablation; 41 focal lesions in 34 patients were treated by TACE; while combined TACE-MWA therapy was performed on 37 focal lesions in 34 patients.

No statistically significant differences $(P>0.05)$ were seen among all studied groups regarding age, sex, viral markers, Child-Pugh Score, laboratory parameters and size of focal lesion. The representative images of the treatment procedures are shown in (Figures $\mathbf{1}$ and 2)

\section{Complications and safety}

All patients successfully received MWA monotherapy, TACE mono-therapy or combined TACE-MWA. There were no procedure-related deaths or major complications in all groups. Hospital stay was not necessary as all of the observed complications were mild, transient and self-limiting. No statistically significant differences $(P>0.05)$ were noted among all studied groups regarding procedure-related complications (fever, vomiting, ascites, pleural effusion and bleeding) apart from transient abdominal pain which was significantly higher in MWA group (32.4\%, $\mathrm{P}=0.02)$. One patient (2.9\%) had minor bleed related to the ablation procedure in the combined TACE-MWA group. Furthermore, there was no statistically significant differences among all studied groups regarding values of bilirubin $(P=0.6)$ and alanine aminotransfersae (ALT) $(P=0.2)$ which indicate that any of the treatment procedure has no significant effect on hepatic function. AFP levels showed improvement but the results were nonsignificant among the studied groups $(P=0.9)$ (Table 2).

\section{Therapeutic tumor response and progression}

The therapeutic tumor response was followed at one month, and every 3 months, up to one year after treatment. Before the end point of the study, 4 patients were died in all groups. All deaths resulted from cirrhosis-related complications (repeated attacks of bleeding (one patient); terminal hepatic failure and hepatorenal syndrome in 3 patients). 
Rates of complete response (CR), partial response (PR) and progressive disease (PR) among the study groups were summarized in (Table 2). After one year follow up; the combined TACE-MWA group showed a non-significant higher rate of complete response (CR) (83.3\%) when compared to MWA group $(76.5 \%)$ and TACE group $(66.6 \%)(P>0.05)$; furthermore, there was a nonsignificant lower rate of the local tumor progression (LTP) in the combined TACE-MWA group (16.6\%) when compared to MWA group $(23.5 \%)$ and TACE group (33.3\%) $(P=0.2)$.

\section{Overall survival rate (OS rate)}

There was no statistically significant difference $(P=0.4)$ among all studied groups regarding OS rate. Both MWA group and combined TACEMWA group had same OS rate $(97.1 \%)$, while

TACE group had $94.1 \%$ OS rate.
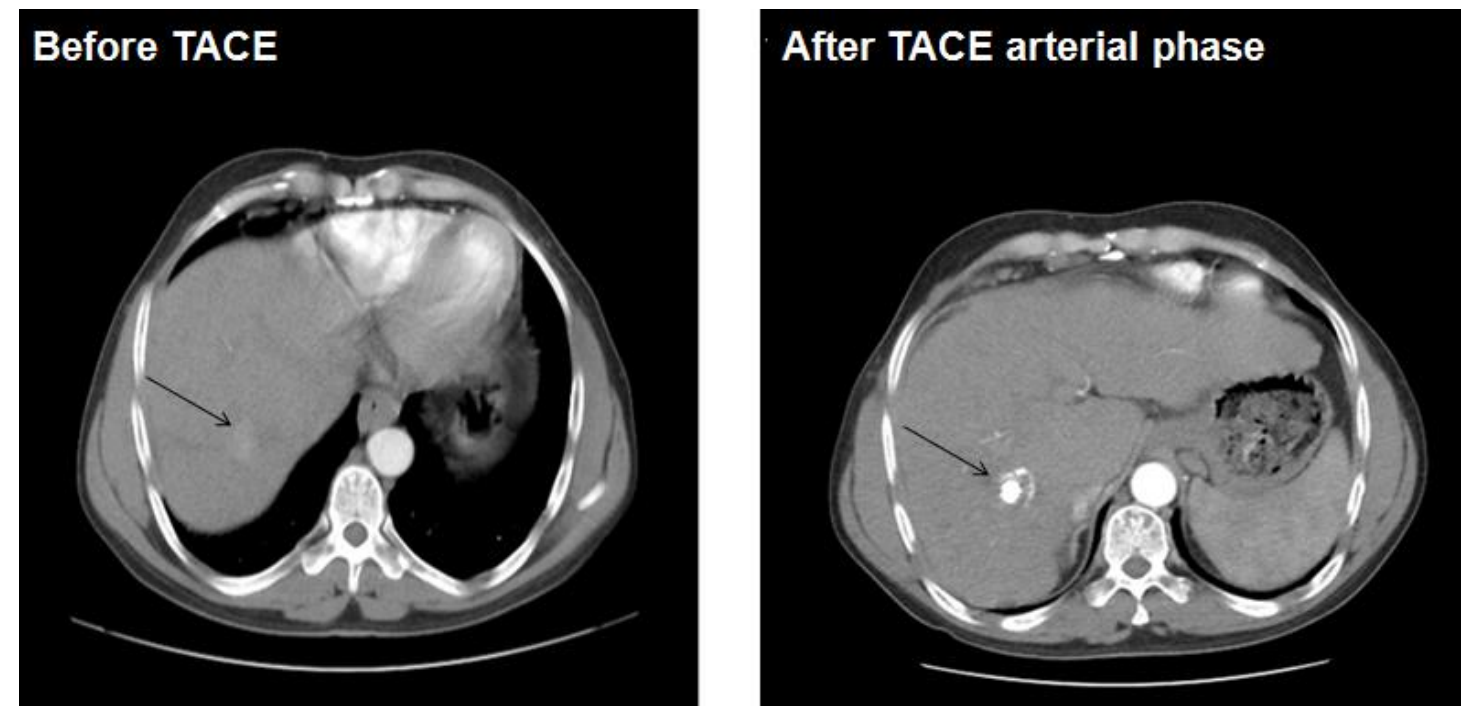

Figure (1): A 50-year old male presented with $4.8 \mathrm{~cm} \mathrm{HCC}$, TACE mono-therapy was performed with complete lipidol uptake after one month.
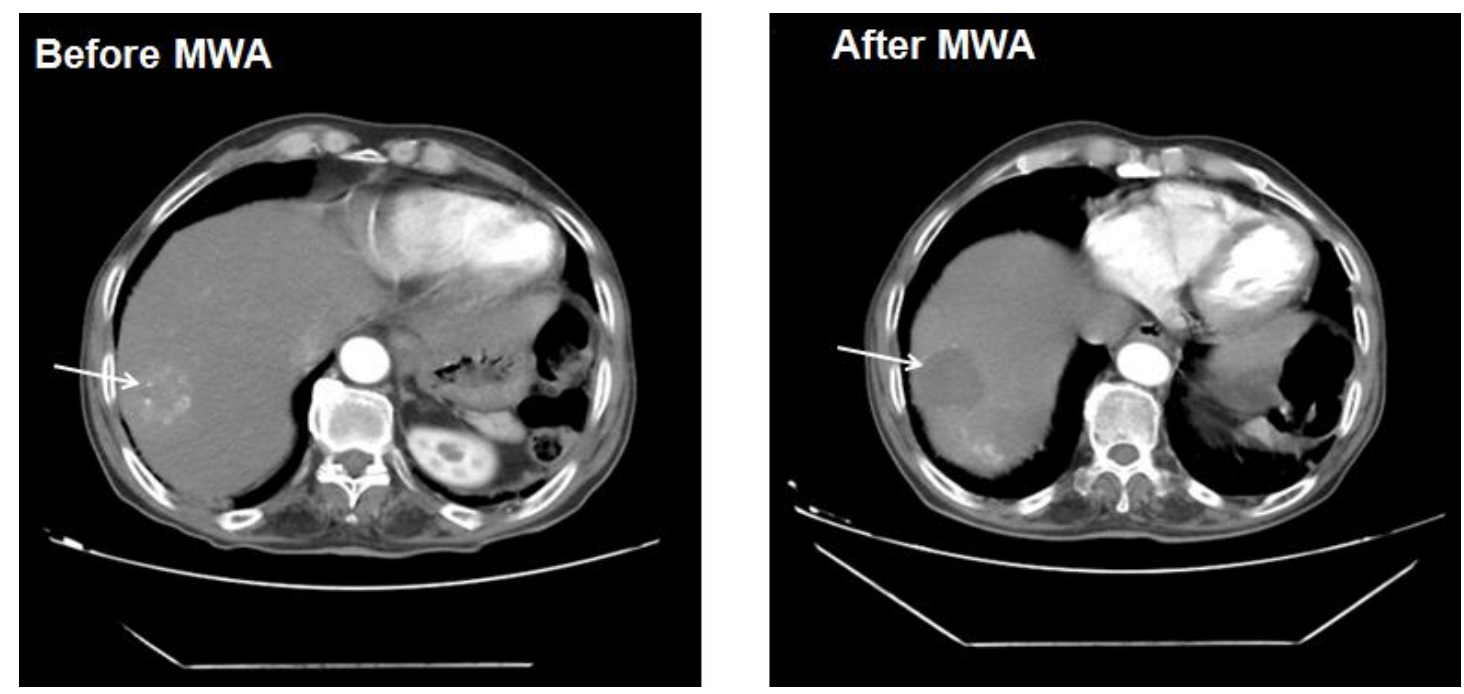

Figure (2): A 67-year old male presented with $4.5 \mathrm{~cm}$ HCC, MWA mono-therapy was performed with complete ablation of the tumor after one month. 
Table (1): Demographic and baseline characteristics of all studied groups.

\begin{tabular}{|c|c|c|c|c|}
\hline Factor & $\begin{array}{c}\text { MWA } \\
(\mathrm{n} .=34)\end{array}$ & $\begin{array}{c}\text { TACE } \\
(\mathrm{n} .=34)\end{array}$ & $\begin{array}{c}\text { TACE+MWA } \\
(\mathrm{n} .=34)\end{array}$ & $P$ value \\
\hline Total number of FL & 35 & 41 & 37 & \\
\hline \multicolumn{5}{|l|}{ Number of FL/Patient } \\
\hline 1 & $97.1 \%(33 / 34)$ & $88.2 \%(30 / 34)$ & $94.1 \%(32 / 34)$ & \multirow[t]{3}{*}{0.4} \\
\hline 2 & $2.9 \%(1 / 34)$ & $2.9 \%(1 / 34)$ & $2.9 \%(1 / 34)$ & \\
\hline 3 & 0.0 & $8.8 \%(3 / 34)$ & $2.9 \%(1 / 34)$ & \\
\hline \multicolumn{5}{|l|}{ Age (years) } \\
\hline Mean \pm SD & $58.7 \pm 5.9$ & $56.3 \pm 6.7$ & $59.4 \pm 7.4$ & \multirow{2}{*}{0.08} \\
\hline Range & $(49-71)$ & $(45-70)$ & $(47-73)$ & \\
\hline \multicolumn{5}{|l|}{ Sex } \\
\hline Male & $79.4 \%(27 / 34)$ & $91.2 \%(31 / 34)$ & $85.3 \%(29 / 34)$ & \multirow{2}{*}{0.9} \\
\hline Female & $20.6 \%(7 / 34)$ & $8.8 \%(3 / 34)$ & $14.7 \%(5 / 34)$ & \\
\hline \multicolumn{5}{|l|}{ Viral markers } \\
\hline Positive HCV & $91.2 \%(31 / 34)$ & $85.3 \%(29 / 34)$ & $94.1 \%(32 / 34)$ & \multirow{3}{*}{0.2} \\
\hline Positive HBV & $8.8 \%(3 / 34)$ & $11.8 \%(4 / 34)$ & 0.0 & \\
\hline $\mathrm{HBV}$ and $\mathrm{HCV}$ & 0.0 & $2.9 \%(1 / 34)$ & $5.9 \%(2 / 34)$ & \\
\hline \multicolumn{5}{|l|}{ Child-Pugh Score } \\
\hline $\mathrm{A}$ & $55.9 \%(19 / 34)$ & $52.9 \%(18 / 34)$ & $58.8 \%(20 / 34)$ & \multirow{2}{*}{0.9} \\
\hline B & $44.1 \%(15 / 34)$ & $47.1 \%(16 / 34)$ & $41.2 \%(14 / 34)$ & \\
\hline $\mathbf{A F P}(\mathrm{ng} / \mathrm{mL})$ & $206.1 \pm 248.8$ & $208.1 \pm 259$ & $203 \pm 248.3$ & 0.9 \\
\hline Bilirubin (mg/dL) & $1.16 \pm 0.55$ & $1.04 \pm 0.28$ & $1.14 \pm 0.46$ & 0.5 \\
\hline ALT (IU/L) & $39.5 \pm 17.5$ & $34.6 \pm 24.1$ & $38.2 \pm 25.2$ & 0.2 \\
\hline Size of FL $(\mathrm{cm})$ & $3.9 \pm 0.6$ & $4.1 \pm 1$ & $4.3 \pm 0.7$ & 0.21 \\
\hline $\begin{array}{l}\mathrm{n} .=\text { number of patients } \\
\text { No statistical significant di }\end{array}$ & & $=$ focal lesion & & \\
\hline
\end{tabular}

Table (2): Follow up data and tumor response in all studied groups.

\begin{tabular}{|c|c|c|c|c|}
\hline Factor & $\begin{array}{c}\text { MWA } \\
(\mathrm{n} .=34)\end{array}$ & $\begin{array}{c}\text { TACE } \\
(\mathrm{n} .=34)\end{array}$ & $\begin{array}{c}\text { TACE+MWA } \\
(\mathrm{n} .=34)\end{array}$ & $\begin{array}{c}\mathbf{P} \\
\text { value }\end{array}$ \\
\hline \multicolumn{5}{|l|}{ Procedure-related complications } \\
\hline Abdominal Pain & $32.4 \%(11 / 34)$ & $5.9 \%(2 / 34)$ & $20.6 \%(7 / 34)$ & $0.02 *$ \\
\hline Fever & $11.8 \%(4 / 34)$ & $20.6 \%(7 / 34)$ & $23.5 \%(8 / 34)$ & 0.4 \\
\hline Vomiting & $2.9 \%(1 / 34)$ & $11.8 \%(4 / 34)$ & $14.7 \%(5 / 34)$ & 0.2 \\
\hline Ascites & $5.9 \%(2 / 34)$ & 0.0 & $2.9 \%(1 / 34)$ & 0.3 \\
\hline Pleural effusion & $2.9 \%(1 / 34)$ & $2.9 \%(1 / 34)$ & $5.9 \%(2 / 34)$ & 0.8 \\
\hline Bleeding & 0.0 & 0.0 & $2.9 \%(1 / 34)$ & 0.3 \\
\hline $\mathbf{A F P}(\mathrm{ng} / \mathrm{mL})$ & $199.1 \pm 238.4$ & $200.5 \pm 235.8$ & $197.4 \pm 231.4$ & 0.9 \\
\hline Bilirubin (mg/dL) & $1.09 \pm 68$ & $1.02 \pm 0.42$ & $0.9 \pm 0.43$ & 0.6 \\
\hline ALT (IU/L) & $32.1 \pm 26.1$ & $22.3 \pm 13.1$ & $34.6 \pm 19.4$ & 0.2 \\
\hline Total number of deaths & $2.9 \%(1 / 34)$ & $5.9 \%(2 / 34)$ & $2.9 \%(1 / 34)$ & 0.8 \\
\hline \multicolumn{5}{|l|}{ Tumor response (at one year/end point)** } \\
\hline $\mathrm{CR}$ & $76.5 \%(26 / 34)$ & $66.6 \%(26 / 39)$ & $83.3 \%(30 / 36)$ & 0.4 \\
\hline PR & $17.6 \%(6 / 34)$ & $23.1 \%(9 / 39)$ & $8.3 \%(3 / 36)$ & \\
\hline $\mathrm{PD}$ & $5.9 \%(2 / 34)$ & $10.3 \%(4 / 39)$ & $8.3 \%(3 / 36)$ & \\
\hline LTP rate (at one year/end point) & $23.5 \%(8 / 34)$ & $33.3 \%(13 / 39)$ & $16.6 \%(6 / 36)$ & 0.2 \\
\hline OS rate $(\%)$ at 1 year & $97.1 \%(33 / 34)$ & $94.1 \%(32 / 34)$ & $97.1 \%(33 / 34)$ & 0.4 \\
\hline \multicolumn{5}{|c|}{$\begin{array}{ll}\text { No statistical significant difference }(\mathrm{P}>0.05) & \mathrm{CR}=\text { complete response }\end{array}$} \\
\hline \multicolumn{5}{|l|}{ * Statistical significant difference $(\mathrm{P} \leq 0.05)$} \\
\hline \multicolumn{5}{|c|}{$\begin{array}{l}\text { LTP= local tumor progression } \\
* * \text { The number of focal lesion in MWA group=34, TACE group= }=39 \text {, Combined TACE-MWA=36; after subtracting the case } \\
\text { of deaths. }\end{array}$} \\
\hline
\end{tabular}




\section{DISCUSSION}

MWA and TACE are established therapies for the treatment of HCC patients. TACE is one of the therapies used for the treatment of un-resectable large-sized HCC as well as treatment of intermediate stage and multifocal tumors $[\mathbf{2 1}, \mathbf{2 5}, \mathbf{2 6}]$. However, complete response is difficult to be achieved by TACE for medium, large or multiple tumors. TACE may results in incomplete occlusion of the tumor-supplying artery with generation of small new collaterals for tumor remnants, or may results in complete occlusion of the tumor-supplying arteries with regeneration of various arterioles from other sites (gastric, superior mesenteric, phrenic, and intercostal arteries) $[\mathbf{2 7 , 2 8}]$ making it difficult to selectively catheterize tumor-feeding arteries to control residual tumor cells. On the other hand, MWA is an effective local thermal ablation technique which has been widely used for treatment of HCC [29-31] with a 5-year survival rate comparable to that of hepatectomy for small hepatic tumors [32]. Microwave ablation produces higher temperature in a shorter period and achieves larger ablation zones when compared with radiofrequency ablation $[\mathbf{3 3}, 34]$.

The present study revealed that using MWA after TACE shows increased rate of CR and low rate of LTP when compared to MWA mono-therapy or TACE mono-therapy in the treatment of 3-5 cm HCC although the differences were not statistically significant.

Regarding tumor response to different therapeutic techniques, this study revealed that the combined TACE-MWA group has a non-significant higher rate of CR $(83.3 \%)$ for $3-5 \mathrm{~cm}$ HCC when compared to MWA mono-therapy group $(76.5 \%)$ and TACE mono-therapy group $(66.6 \%)(P=0.4)$. These results compare favorably with Smolock et al., who included same range of tumor sizes, from 3-5 $\mathrm{cm}$, and reported higher $\mathrm{CR}$ rate in the combined TACE-MWA $(65 \% ; 15 / 23)$ versus TACE mono-therapy $(38 \% ; 9 / 24)(P=0.12)$ [35]. Furthermore, our study had a higher $\mathrm{CR}$ rate than that reported by $\mathbf{L i}$ et al., who included larger tumors (mean size approximately $7 \mathrm{~cm}$ ) treated with TACE+MWA $(65 \% \mathrm{CR})$ versus TACE mono-therapy (45\% CR) [18].

The increased CR that was noted in the combined TACE-MWA group may be resulting from the complementary effect of both procedures. Prior studies revealed that chemotherapeutic agents may cause a heat-sensitizing effect and thermal injury may sensitize tumors to these agents. In addition, larger necrotic zones have been demonstrated when TACE was followed by ablation rather than the converse [36,37]. In the present study, MWA was done 2 weeks after TACE, to facilitate targeting of the tumor by ultrasound with higher possibility for accurate placement of the ablation probes in the tumor (time allows enhanced contrast between the Lipiodol-stained tumor and surrounding liver tissue). Moreover, time allows patient to recover from any symptoms that may occur after TACE $[35,38]$.

Based on post-treatment cross-sectional imaging findings, TACE-MWA group showed lower LTP rate $(16.6 \%)$ when compared to MWA monotherapy group (23.5\%) and TACE mono-therapy group (33.3\%) $(P=0.2)$. These results are in agreement with Smolock et al., who compared TACE mono-therapy with combined simultaneous TACE and MWA and demonstrated lower rate of LTP in the tumors treated with combined TACE and MWA (34.8\%) than tumors treated with TACE alone $(62.5 \%)(P=0.1)$ [35]. Furthermore, a retrospective study involved 258 patients with a large solitary nodule or multinodular HCCs ( $\leq 10$ nodules), and treated by TACE-MWA $(n=92)$ or TACE alone $(n=166)$, revealed $47.8 \%$ one year recurrence rate in the TACE-MWA group versus $74.7 \%$ in the TACE group $(P<0001)$ [39].

In the current study, no significant survival advantage was noted among the groups as the follow up period was one year. Both MWA group and combined TACE-MWA group had same OS rate $(97.1 \%)$, while TACE group had $94.1 \%$ OS rate $(P=0.4)$. These results are comparable with Chen et al., who reported $91.7 \%$ cumulative survival rate after one year in the combined TACE-MWA group versus $87.2 \%$ in TACE mono-therapy group $(\mathrm{P}=0.3)$ [40]. In contrast, other studies demonstrated significant higher OS rates with the combined TACE-MWA therapy versus TACE mono-therapy. Xu et al.; Zhang et al. and Zheng et al., reported higher OS rates at 1-year for TACE-MWA group (87.5\%; $93.1 \%$ and $85.9 \%$ respectively) than that for TACE group $(62.5 \% ; 77.5 \%$ and $59 \%$ respectively) $(\mathrm{P}<0.001)$ $[39,41,42]$. 
Both TACE and MWA are minimally invasive procedures with uncommon major complications and rare mortalities $[\mathbf{4 3 , 4 4 ]}$. Although performing two procedures may add more risk with each procedure, this study reported minor complications related to both MWA and TACE procedures with no statistically significant differences $(\mathrm{P}>0.05)$ noted among all studied groups apart from significant increase in abdominal pain $(32.4 \%, P=0.02)$ with microwave mono-therapy that may be attributed to the site of lesion (subcapsular or peri-hilar) and the amount of tissue necrosis [45]. In addition, this study showed no procedure-related deaths or serious major events in all groups and this is consistent with Liu et al., who stated that all patients tolerated both TACE and MWA procedure well without any fatal or major complications [46]. On the other hand, Zheng and his colleagues reported major complications in 3.6\% (6/166) of patients treated with TACE mono-therapy versus $2.2 \%(2 / 92)$ of patients treated with combined TACE-MWA therapy [39], which may be related to the higher number of patients in their study.

Furthermore, the current study showed no statistically significant differences among all studied groups regarding values of bilirubin $(P=0.6)$ and ALT $(P=0.2)$. These results are similar to Smolock et al., who reported that bilirubin values showed no difference after treatment and no change in-between the groups $(P=0.6)$ indicating that any of the treatment procedure has no significant hepatocyte damage [35].

Post-treatment hypoxia and tumor necrosis has been shown to lead to AFP decrease $[47,48]$. In the present study, non-significant improvement in the post-treatment AFP levels was noted among the different studied groups $(P=0.9)$. Moreover, a study done by $\mathbf{X u}$ et al., showed significant reduction in AFP level after treatment with combined TACE-MWA therapy $(P<0.001)$ and TACE mono-therapy $(P=0.003)$ [41]. This decrease in AFP levels may predict advantageous therapeutic effect [49].

To the best of authors' knowledge, this is the first study to compare 3 groups (MWA mono-therapy, TACE mono-therapy and combined TACEMWA) for treatment of HCC, while most of the studies compared only 2 groups (TACE monotherapy versus combined TACE-MWA). Furthermore, our study is a prospective non- randomized study unlike most of other studies that were retrospective.

The study has certain limitations. First, the follow-up period was one year with limited survival data and this may have led to biased results. Also, there was a difference in the disease burden among the studied groups with more multifocal disease in TACE mono-therapy group. In addition, all procedures were performed by the same HCC management team in our institution, with the possibility of bias from doctors' experience, patients' characteristics and equipments' quality.

\section{CONCLUSION}

This study demonstrated that despite both combined TACE-MWA therapy and MWAmono-therapy had the same OS rate, however, combined TACE-MWA therapy appears to be non-significantly superior to MWA mono-therapy and TACE mono-therapy in terms of complete tumor response and local tumor progression in patients with 3-5 cm HCC. Further multi-centre prospective randomized controlled trials with longer follow up periods are needed.

\section{Conflict of interest: None.}

Financial disclosure: None.

Ethical considerations: Approval of Institutional Review Board of the Faculty of Medicine, Zagazig University was granted. Consent was obtained from patients before the procedure after explaining risk/benefit ratio as well as the expected hazards and interventions.

\section{REFERENCES}

1. Ferenci P, Fried M, Labrecque D, Bruix J, Sherman M, Omata M. et al. Hepatocellular carcinoma (HCC): a global perspective. J. Clin. Gastroenterol 2010; 44: 239-45.

2. Jemal A, Bray F, Center MM, Ferlay J, Ward E, Forman D. Global cancer statistics. CA Cancer $J$ Clin 2011; 61: 69-90.

3. Millonig G, Graziadei IW, Freund MC, Jaschke W, Stadlmann S, Ladurner R. et al. Response to preoperative chemoembolization correlates with outcome after liver transplantation in patients with hepatocellular carcinoma. Liver Transpl 2007; 13(2): 272-9. 
4. She WH, Cheung TT. Bridging and downstaging therapy in patients suffering from hepatocellular carcinoma waiting on the list of liver transplantation. Transl Gastroenterol Hepatol 2016; 1: 34.

5. Affonso BB, Galastri FL, da Motta Leal Filho JM, Nasser F, Falsarella PM, Cavalcante RN. et al. Long-term outcomes of hepatocellular carcinoma that underwent chemoembolization for bridging or downstaging. World J Gastroenterol 2019; 25(37): 5687-701.

6. Llovet JM, Fuster J, and Bruix J. The Barcelona Approach: Diagnosis, Staging, and Treatment of Hepatocellular Carcinoma. Liver Transplantation 2004; 10 (suppl 1): pp S115-20.

7. Bruix J, Sherman M. Management of hepatocellular carcinoma: an update. Hepatology 2011; 53(3): 1020-22.

8. Lei JY, Yan LN, Wang WT. Transplantation versus resection for hepatocellular carcinoma with compensated liver function after downstaging therapy. World J Gastroenterol 2013; 19(27): 4400-8.

9. Kothary N, Takehana C, Mueller K, Sullivan P, Tahvildari A, Sidhar V, et al. Watershed hepatocellular carcinomas: the risk of incomplete response following transhepatic arterial chemoembolization. J Vasc Interv Radiol 2015; 26(8): 1122-29.

10. Kim JH, Won HJ, Shin YM, Kim SH, Yoon HK, Sung KB, et al. Medium-sized $(3.1-5.0 \mathrm{~cm})$ hepatocellular carcinoma: transarterial chemoembolization plus radiofrequency ablation versus radiofrequency ablation alone. Ann Surg Oncol 2011; 18: 1624-9.

11. Ni JY, Liu SS, Xu LF, Sun HL, Chen YT. Metaanalysis of radiofrequency ablation in combination with transarterial chemo-embolization for hepatocellular carcinoma. World J Gastroenterol 2013; 19(24): 3872-82.

12. Peng ZW, Zhang YJ, Chen MS, Xu L, Liang HH, Lin XJ, et al. Radiofrequency ablation with or without transcatheter arterial chemoembolization in the treatment of hepatocellular carcinoma: a prospective randomized trial. J Clin Oncol 2013; 31(4): 426-32.

13. Brace CL. Radiofrequency and microwave ablation of the liver, lung, kidney, and bone: what are the differences? Curr Probl Diagn Radio 2009; 138(3): 135-43.

14. Abdelaziz AO, Abdelmaksoud AH, Nabeel MM, Shousha HI, Cordie AA, Mahmoud ShH, et al. Transarterial chemoembolization combined with either radiofrequency or microwave ablation in management of hepatocellular carcinoma. Asian Pac J Cancer Prev 2017; 18: 189-94.
15. Seki $T$, Tamai $T$, Nakagawa $T$, Imamura $M$, Nishimura A, Yamashiki $\mathrm{N}$, et al. Combination therapy with transcatheter arterial chemoembolization and percutaneous microwave coagulation therapy for hepatocellular carcinoma. Cancer 2000; 89(6): 1245-51.

16. Yang WZ, Jiang N, Huang N, Huang, JY, Zheng, $\mathrm{QB}$, Shen Q. Combined therapy with transcatheter arterial chemoembolization and percutaneous microwave coagulation for small hepatocellular carcinoma. World J Gastroenterol 2009; 15(6): 748-52.

17. Ginsburg M, Zivin SP, Wroblewski K, Doshi T, Vasnani RJ, Van Ha TG. Comparison of combination therapies in the management of hepatocellular carcinoma: transarterial chemoembolization with radiofrequency ablation versus microwave ablation. $J$ Vasc Interv Radiol 2015; 26(3): 330-41.

18. Li W, Man W, Guo H, Yang P (2016): Clinical study of transcatheter arterial chemoembolization combined with microwave ablation in the treatment of advanced hepatocellular carcinoma. $J$ Cancer Res Ther 2016; 12(Supplement): C217C220.

19. Oken, M.; Creech, R.; Tormey, D. Horton J, Davis TE McFadden E, et al. Toxicity and response criteria of the Eastern Cooperative Oncology Group. Am J Clin Oncol 1982; 5 (6): 649-55.

20. Pugh RN, Murray-Lyon IM, Dawson JL, Pietroni MC, Williams R. Transection of the oesophagus for bleeding oesophageal varices. Br J Surg 1973; 60(8): 646-9.

21. EASL-EORTC clinical practice guidelines. Management of hepatocellular carcinoma. $J$ Hepatol 2012; 56 (4): 908-43.

22. Gonzalez-Guindalini FD, Botelho MP, Harmath CB, Sandrasegaran K, Miller FH, Salem R, et al. Assessment of Liver Tumor Response to Therapy: Role of Quantitative Imaging. Radiographics 2013; 33(6): 1781-800.

23. Ahmed M. Image-guided tumor ablation: standardization of terminology and reporting criteria-a 10-year update: supplement to the consensus document. J Vasc Interv Radiol 2014; 25(11): 1706-8.

24. Sacks D, McClenney TE, Cardella JF, Lewis CA. Society of Interventional Radiology clinical practice guidelines. J Vasc Interv Radiol 2003; 14 : S199-S202.

25. Farinati F, De Maria N, Marafin C, Herszènyi L, Del Prato S, Rinaldi M, et al. Unresectable hepatocellular carcinoma in cirrhosis: Survival, prognostic factors, and unexpected side effects after transcatheter arterial chemoembolization. Dig Dis Sci 1996; 41(12): 2332-9.

26. Okada S. Transcatheter arterial embolization for advanced hepatocellular carcinoma: The controversy continues. Hepatology 1998; 27: 1743-4. 
27. Wang W, Shi J, Xie WF. Transarterial chemoembolization in combination with percutaneous ablation therapy in unresectable hepatocellular carcinoma: a meta-analysis. Liver Int 2010; 30: 741-9.

28. Zhao M, Wang JP, Pan CC, Li W, Huang ZL, Zhang L, et al. CT-guided radiofrequency ablation after with transarterial chemoembolization in treating unresectable hepatocellular carcinoma with long overall survival improvement. Eur J Radiol 2012; 81: 2717-25.

29. Ren H, Liang P, Yu X, Wang Y, Lu T, Li X. Treatment of liver tumours adjacent to hepatic hilum with percutaneous microwave ablation combined with ethanol injection: A pilot study. Int J Hyperthermia 2011; 27(3): 249-54.

30. Liu FY, Yu XL, Liang P, Wang Y, Zhou P, Yu J. Comparison of percutaneous $915 \mathrm{MHz}$ microwave ablation and $2450 \mathrm{MHz}$ microwave ablation in large hepatocellular carcinoma. Int $J$ Hyperthermia 2010; 26(5): 448-55.

31. Dong B, Liang P, Yu X, Su L, Yu D, Cheng Z, et al. Percutaneous sonographically guided microwave coagulation therapy for hepatocellular carcinoma: Results in 234 patients. AJR 2003; 180: 1547-55.

32. Liang P, Dong B, Yu X, Yu D, Wang Y, Feng L, et al. Prognostic factors for survival in patients with hepatocellular carcinoma after percutaneous microwave ablation. Radiology 2005; 235: 299307.

33. Goldberg SN, Gazelle GS, Mueller PR. Thermal ablation therapy for focal malignancy: a unified approach to underlying principles, techniques, and diagnostic imaging guidance. AJR 2000; 174(2): 323-31.

34. Liang $\mathrm{P}$, Wang $\mathrm{Y}$. Microwave ablation of hepatocellular carcinoma. Oncology 2007; 72(Suppl 1): 124-31.

35. Smolock AR, Cristescu MM, Hinshaw A, Woo KM, Wells SA, Ziemlewicz TJ, et al. Combination transarterial chemoembolization and microwave ablation improves local tumor control for 3- to 5$\mathrm{cm}$ hepatocellular carcinoma when compared with transarterial chemoembolization alone. Abdom Radiol (NY) 2018; 43(9): 2497-504.

36. Goldberg SN, Saldinger PF, Gazelle GS, Huertas JC, Stuart KE, Jacobs T, et al. Percutaneous tumor ablation: increased necrosis with combined radiofrequency ablation and intratumoral doxorubicin injection in a rat breast tumor model. Radiology 2001; 220(2): 420-7.

37. Mostafa EM, Ganguli S, Faintuch S, Mertyna P, Goldberg SN. Optimal strategies for combining transcatheter arterial chemoembolization and radiofrequency ablation in rabbit VX2 hepatic tumors. J Vasc Interv Radiol 2008; 19(12): 174048.
38. Agopian VG, Harlander-Locke MP, Ruiz RM, Klintmalm GB, Senguttuvan S, Florman SS, et al. Impact of Pretransplant Bridging Locoregional Therapy for Patients With Hepatocellular Carcinoma Within Milan Criteria Undergoing Liver Transplantation: Analysis of 3601 Patients From the US Multicenter HCC Transplant Consortium. Ann Surg 2017; 266(3): 525-35.

39. Zheng L, Li HL, Guo CY, Luo SX. Comparison of the efficacy and prognostic factors of transarterial chemoembolization plus microwave ablation versus transarterial chemoembolization alone in patients with a large solitary or multinodular hepatocellular carcinomas. Korean J Radiol 2018; 19(2): 237-246.

40. Chen QF, Jia ZY, Yang ZQ, Fan WL, Shi HB. Transarterial Chemoembolization Monotherapy Versus Combined Transarterial Chemoembolization-Microwave Ablation Therapy for Hepatocellular Carcinoma Tumors $\leq 5 \mathrm{~cm}$ : A Propensity Analysis at a Single Center. Cardiovasc Intervent Radiol 2017; 40(11): 174855.

41. Xu LF, Sun HL, Chen YT, Ni JY, Chen D, Luo $\mathrm{JH}$, et al. Large primary hepatocellular carcinoma: transarterial chemoembolization monotherapy versus combined transarterial chemoembolization percutaneous microwave coagulation therapy. $J$ Gastroenterol Hepatol 2013; 28: 456-63.

42. Zhang R, Shen L, Zhao L, Guan Z, Chen Q, Li W. Combined transarterial chemoembolization and microwave ablation versus transarterial chemoembolization in BCLC stage B hepatocellular carcinoma. Diagn Interv Radiol 2018; 24(4): 219-24.

43. Clark TW. Complications of hepatic chemoembolization. Semin Intervent Radiol 2006; 23(2): 119-25.

44. Bertot LC, Sato M, Tateishi R, Yoshida H, Koike K. Mortality and complication rates of percutaneous ablative techniques for the treatment of liver tumors: a systematic review. Eur Radiol 2011; 21(12): 2584-96.

45. Poggi G, Tosoratti N, Montagna B, Picchi C. Microwave ablation of hepatocellular carcinoma. World J Hepatol; 2015, 7(25): 2578-89.

46. Liu C, Liang P, Liu F, Wang Y, Li X, Han Z, et al. MWA combined with TACE as a combined therapy for unresectable large-sized hepotocellular carcinoma. Int J Hyperthermia 2011; 27(7): 65462.

47. Mazure NM, Chauvet C, Bois-Joyeux B, Bernard MA, Nacer-Cherif H, Danan JL. Repression of alpha-fetoprotein gene expression under hypoxic conditions in human hepatoma cells: characterization of a negative hypoxia response element that mediates opposite effects of hypoxia inducible factor-1 and c-Myc. Cancer Res 2002; 62: 1158-65. 
48. Memon K, Kulik L, Lewandowski RJ, Wang E, Ryu RK, Riaz A, et al. Alpha-fetoprotein response correlates with EASL response and survival in solitary hepatocellular carcinoma treated with transarterial therapies: a subgroup analysis. $J$ Hepatol 2012; 56(5): 1112-120.
49. He C, Zhang X, Li C, Peng W, Wen TF, Yan LN, et al. Changes of alpha-fetoprotein levels could predict recurrent hepatocellular carcinoma survival after trans-arterial chemo-embolization. Oncotarget 2017; 8(49): 85599-611. 